\title{
RESENHA
}

\section{Escola, família e mediação profissional na inclusão escolar de crianças com Síndrome de Down}

School inclusion of children with Down Syndrome: the role of school, family and professional mediation

\author{
Fernanda Cascaes Teixeira \\ Olga Mitsue Kubo \\ Universidade Federal de Santa Catarina
}

Voivodic, M. A. M. A. (2004). Inclusão escolar de crianças com Sindrome de Down. Petrópolis: Vozes.

Leis e normas políticas são suficientes para garantir ao indivíduo com necessidades educacionais especiais a inclusão no sistema regular de ensino? Dados do Censo Escolar de 2002, divulgados pelo Instituto Nacional de Estudos e Pesquisas Educacionais (Inep), revelam que enquanto 400.000 alunos com algum tipo de deficiência estudam em escolas especiais, apenas 110.000 freqüentam escolas regulares, embora a política educacional brasileira evidencie uma preocupação com a "educação para todos" preferencialmente em classes comuns. Se leis e normas políticas não garantem a inclusão escolar de pessoas com necessidades educacionais especiais, quais seriam então as condições facilitadoras desse processo? A psicóloga e pedagoga Maria Antonieta Voivodic tem a resposta. Em seu livro Inclusão escolar de crianças com Síndrome de Down, a autora avalia o projeto "Educar Mais 1" e apresenta ao leitor procedimentos efetivos para a concretização da inclusão escolar.

O projeto "Educar Mais 1" tem como objetivo a inclusão de crianças com Síndrome de Down em classes comuns do ensino regular e, para tanto, estabelece ações de mediação de profissionais da Psicologia e da Pedagogia nos contextos familiar e escolar. A partir da iniciativa de um grupo de pais, o projeto teve início em maio de 1998, utilizando como diretriz a teoria e o método do "Projeto Roma", desenvolvido em Málaga, na Espanha. As primeiras crianças participantes, em idade pré-escolar, ingressaram em escolas regulares da cidade de Campinas, em São Paulo, no primeiro semestre de 2002. Em 1999, um grupo de profissionais do projeto "Educar Mais 1" foi formado em Belo Horizonte e, em 2001, na cidade de São Paulo. No projeto, foram estabelecidas algumas normas para o seu desenvolvimento como a participação e comprometimento de pais e professores.

O contato entre a família e os profissionais da escola, na qual a criança com Síndrome de Down estuda, é estabelecido por um mediador, um pedagogo, que estará na escola com a criança uma vez por semana para observar a turma na qual ela está inserida, sem interferir na aula ministrada pelo professor, que é o condutor do processo de aprendizagem. Além disso, o mediador tem reuniões com o professor e profissionais (fonoaudiólogo, terapeuta) que acompanham a criança, contatos semanais com os pais e com o coordenador do projeto (um psicólogo). Dessa forma, o mediador apóia a família, o professor e indiretamente a criança. Por sua vez, o coordenador apóia o mediador. As ações promovidas pelo projeto "Educar Mais 1" facilitam o diálogo entre a família, a escola e os profissionais especialistas, com o objetivo de unir esforços para a concretização da inclusão escolar de crianças com Síndrome de Down.

Maria Antonieta Voivodic desenvolveu uma pesquisa qualitativa, com o intuito de avaliar o desenvolvimento e a eficácia do projeto "Educar Mais 1". A autora não apenas apresenta ao leitor aspectos facilitadores da inclusão escolar, como também a possibilidade de aperfeiçoá-los. A partir dos resultados de sua pesquisa, Maria Antonieta conclui que a inclusão é um processo gradativo e que, embora as escolas aceitem a criança com deficiência, elas não estão preparadas para propiciar as condições necessárias para o seu desenvolvimento. Isto porque os estereótipos que os pais e os educadores possuem sobre a deficiência difi- 
cultam a inclusão da criança com Síndrome de Down na escola e na própria família. A autora enfatiza a importância do apoio do professor para lidar com o grupo no qual a criança com Síndrome de Down está inserida e, portanto, a necessidade da realização de programas de capacitação profissional e a revisão dos currículos. De acordo com a autora, o primeiro contexto no qual a criança precisa estar inserida é a família. Nesta, em geral, o pai costuma ter maior resistência em aceitar a deficiência da criança.

O Projeto "Educar Mais 1"possui como diferencial em relação a outros projetos o fato de ter sido avaliado por meio de procedimentos sistemáticos que possibilitam aferir com maior precisão seu efeito e, principalmente, aspectos que precisam ser melhorados. Dentre as mudanças sugeridas pela autora para o aperfeiçoamento do projeto é possível destacar: que profissionais da escola sejam capacitados para a realização da mediação com os professores e que a escola financie cursos e oficinas de capacitação para todos os seus funcionários. No trabalho desenvolvido no contexto familiar, a autora sugere que os encontros de mediação passem a ser quinzenais com o objetivo que diminuir os custos e tornar o trabalho menos invasivo. Além disso, a autora ressalta que o fato do projeto ser mantido pelos pais limita sua abrangência e ocasiona um conflito de papéis na relação entre os pais e as mediadoras.

Por fim, o livro de Maria Antonieta, mais que relatar características sobre a Síndrome de Down e teorias acerca de conceitos como integração e inclusão escolar, temas amplamente discutidos na literatura científica, oferece ao leitor estratégias facilitadoras da inclusão empregadas no projeto "Educar Mais 1", que utiliza o referencial prático e teórico do "Projeto Roma", desenvolvido na Espanha. Além de ter sido aplicado em diferentes cidades do Brasil, é um projeto que foi avaliado cientificamente por uma pesquisa desenvolvida pela autora. Dessa forma, o livro constitui-se em bom orientador para a prática de profissionais de Educação e Psicologia, uma vez que nele são apresentados procedimentos efetivos para a concretização da inclusão social.

\section{REFERÊNCIAS}

Voivodic, M. A. M. A. (2004). Inclusão escolar de crianças com Síndrome de Down. Petrópolis: Vozes.

Recebido: 30/10/2005 Revisado: 07/06/2006 Aceito: $25 / 06 / 2006$

\section{Sobre as autoras da resenha:}

Fernanda Cascaes Teixeira: Doutoranda do Programa de Pós-graduação em Psicologia da Universidade Federal de Santa Catarina. Endereço eletrônico: fcate @ terra.com.br.

Olga Mitsue Kubo: Professora do Departamento de Psicologia e do Programa de Pós-graduação em Psicologia da Universidade Federal de Santa Catarina. Endereço eletrônico: ok@cfh.ufsc.br. 